Faculdade de Ciências Econômicas UFRGS

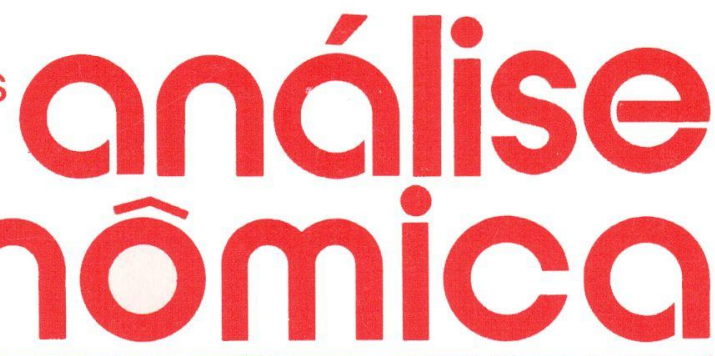

- teoria do balanço de PAGAMENTOS Joáo Luis Tenreiro Barroso

- a IMPORTÂncIa das teorias DE SALÁRIO PARA AS TEORIAS DE INFLAÇÃO Lúcia Maria Góes Moutinho

- os ciclos da economia BRASILEIRA

Vera Beatriz da Silva Oliveira

- SUBSÍDIOS DE PREÇOS AO TRIGO NO BRASIL

Vera Martins da Silva

- A EFICIÊnCIA dA AGRICULtURA GAÚCHA

Juvir Luiz Mattuella

- A economia Regional no BRASIL

Paulo Roberto Haddad

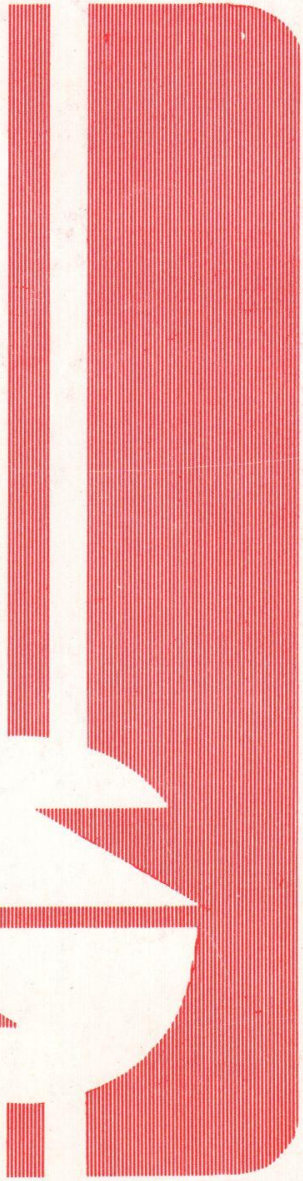


UNIVERSIDADE FEDERAL DO RIO GRANDE DO SUL

Reitor: Prof. Gerhard Jacob

FACULDADE DE CIÊNCIAS ECONÔMICAS

Diretor. Prof. Walter Meucci Nique

CENTRO DE ESTUDOS E PESQUISAS ECONÔMICAS

Diretor: Prof. Reinaldo Ignacio Adams

DEPARTAMENTO DE CIÊNCIAS ECONÔMICAS

Chefe: Profa Oțtlia Beatriz Kroeff Carrion

CURSO DE PÓS-GRADUAÇĀO EM ECONOMIA

Coordenador: Prof. Roberto Camps Moraes

CURSO DE PÓS-GRADUAÇĀO EM ECONOMIA RURAL

Coordenador: Prof. Aray Miguel Feldens

CONSELHO EDITORIAL:

Achyles Barcelos da Costa, Aray Miguel Feldens, Atos Freitas Grawunder, Carlos Augusto Crusius, Ernani Hickmann, João Rogério Sanson, Juvir Luiz Mattuella, Maria Imilda da Costa e Silva, Nali de Jesus de Souza, Nuno Renan Lopes de Figueiredo Pinto, Otília Beatriz Kroeff Carrion, Otto Guilherme Konzen, Paulo Alexandre Spohr, Pedro Cezar Dutra Fonseca, Reinaldo Ignacio Adams, Roberto Camps Moraes, Valter José Stülp, Yeda Rorato Crusius, Edgar Augusto Lanzer (UFSC) e Humberto Vendelino Richeter (UnB)

COMISSĀO EDITORIAL: Atos Freitas Grawunder; Pedro Cezar Dutra Fonseca, Reinaldo Ignacio Adams e Roberto Camps Moraes.

EDITOR: Nali de Jesus de Souza

SECRETARIA: Francisco Carlos Becco dos Santos, Maria Ivone de Mello (normalizaçāo), Vanete Ricacheski (revisão de textos), Wagner Nunes e Zélide Bregaida.

FUNDADOR: Prof. Antônio Carlos Rosa

A Revista ANÁLISE ECONÔMICA publica dois números anuais nos meses de março e novembro. O preço da assinatura, para 1990, é de 7,0 BTNs (o número avulso custa 4 BTNs), a ser pago através de cheque nominal em nome da "Faculdade de Ciências Econômicas/ UFRGS". Aceita-se permuta com revistas congêneres. Aceitam-se, também, livros para elaboração de resenhas ou recensōes.

Toda correspondência, material para publicação, assinaturas e permutas devem ser dirigidos ao seguinte destinatário:

PROF. NALI DE JESUS DE SOUZA

Revista Análise Econômica

Av. João Pessoa, 52 - sala 28

90.040 - PORTO ALEGRE (RS) - BRASIL

Telefone: 25-5844 ramal 34 


\section{A EFICIÊNCIA DA AGRICULTURA GAÚCHA NA DÉCADA DE 80*}

Juvir Luiz Mattuella**

\section{1 - INTRODUÇÃO}

As políticas agrícolas implementadas no Brasil nas últimas décadas objetivaram, via de regra, atender ao crescimento da demanda pelos produtos do setor sem, contudo, se preocupar com possíveis conseqüências sócio-econômicas. Os interesses do setor urbano-industrial e a necessidade de se ampliar o volume de exportáveis, sempre se sobrepuseram aos possiveis desequilibrios sociais e ineficiências econômicas que poderiam estar sendo acalentadas no campo.

A política agrícola apregoada pela 'Nova República' busca, pelo menos no seu nível discursivo, traçar novos rumos para o setor rural. Prioriza a produção voltada para o abastecimento do mercado interno, embora sem prejudicar as lavouras de exportação; procura beneficiar a produção de alimentos básicos e, ao mesmo tempo, melhorar as condiçōes de vida de pequenos e médios produtores que se dedicam à agricultura; pretende alterar as relações na produção, através da implementação de um programa de reforma agrária. Paralelamente, é proposto um redimensionamento da pesquisa agrícola para a busca de técnicas alternativas de produção que, diminuindo a dependência de

" Trabalho apresentado na 6a Reuniăo Regional da SBPC, realizada em Santa Maria (RS), em outubro de 1988.

* Pesquisador do IEPE e professor do Departamento de Economia e do Curso de Pós-Graduação em Economia $\theta$ Economia Rural da UFRǴs.

\begin{tabular}{|l|l|l|l|l|}
\hline ANÁLISE ECONÔMICA & ANO 7 & №11 & MARÇO/89 & p.115-129 \\
\hline
\end{tabular}


insumos industriais, sejam menos agressivas ao meio ambiente e mais atrativas aos produtores de pequeno porte.

Com programas específicos, Microbacias Piloto, por exemplo, buscam-se soluções para o uso mais adequado do solo. Embora disponivel em quantidade fixa, este recurso tem seu fluxo potencial de serviços que dele pode ser obtido no tempo atrelado ao seu uso. A sua fertilidade pode ser melhorada até certos limites, no decorrer do processo produtivo, pelo emprego de técnicas de produção que assim o permitam. Entretanto, também é possivel que ela seja gradativamente exaurida pela utilização de técnicas não conservacionistas, de tal forma que o processo possa até ser irreversivel. Em síntese, o problema econômico básico em relação a este recurso é determinar uma taxa de uso e técnicas de cultivo tais que o fluxo produtivo potencial do mesmo possa se manter, pelo menos, constante ao longo do tempo, embora isto seja diff́cil devido às incertezas peculiares ao setor agrícola, como pelas diferenças nos horizontes de planejamento privados e sociais.

A implementação de um programa agrícola amplo, como o anunciado, levanta diversas questões atinentes aos impactos que causará no setor. A oferta de alimentos e fibras é gerada num conjunto de unidades heterogêneas, tanto em relação a aspectos de ambiente físico como pelo processo produtivo usado e relações sociais na produção. Desta forma, as respostas aos estímulos das políticas agrícolas, dadas por estas unidades produtivas, são as mais variadas, dificultando a avaliação da eficácia das mesmas a nivel agregado. A racionalidade, então, passa a ser buscada dentro de um oneroso processo de tentativas e erros. Essa sistemática, embora esteja relacionada ao processo de tomada de decisão de políticas agrícolas de âmbito nacional, não deixa de ser representativa daquilo que ocorre a nivel local.

Em decorência da problemática, acima delineada, desenvolveramse estudos no IEPE que pudessem colaborar na avaliação do reflexo de algumas políticas econômicas alternativas na agricultura gaúcha, enfocando, principalmente, questōes como: a) eficiência produtiva; b) eficiência do uso do solo. Com base nos resultados destas pesquisas, desenvolveu-se a análise que se segue, onde se examina, inicialmente, aspectos da eficiência produtiva do setor primário do Estado e, posteriormente, a economicidade da consenvação do solo agrícola. Estes dois temas constituem o cerne do presente trabalho. 


\section{2 - EFICIÊNCIA PRODUTIVA'}

Para avaliar a eficiência produtiva da agricultura gaúcha e os efeitos de algumas políticas selecionadas, partiu-se da concepção de que o setor primário pode ser visualizado como sendo composto por diversos processos produtivos que são vertical e horizontalmente integrados. As sucessivas etapas desses processos, desde o inicio da produção até a colocação do produto no mercado, formam a coordenação vertical do mesmo. Porém as funçōes desenvolvidas em cada etapa do sistema vertical competem, por seu turno, com as atividades de outros produtos pelos recursos disponiveis, formando, assim, o elo de integração horizontal entre os diversos processos de integração.

As relaçōes estruturais desta concepção do setor primário foram formuladas num modelo de programação matemática, de forma a caracterizar a representação da situação de um equilibrio geral para o mesmo. A solução do modelo, desta forma, é simultânea para todos os componentes nele programados, dentro das restrições impostas de disponibilidade de recursos existentes e tecnologias empregadas. Assim, possíveis ajustamentos no sistema de produção agrícola podem ser simulados através de alterações nos parâmetros do modelo, e seu impacto verificado pelas mudanças que ocorrem na solução ótima do mesmo. Desta forma, o modelo permite dentro do limite das pressuposições assumidas simular políticas econômicas para o setor e verificar seus possíveis impactos.

O modelo básico, definido para unidades produtivas t́picas, considera como medida de eficiência econômica a minimização do custo de produção, dadas as disponibilidades de recursos existentes e a organização da produção. A sua formulação tem, portanto, o objetivo de determinar o número de unidades produtoras de cada tipo em cada região, de modo que sejam cumpridas as metas de produção, estabelecidas ao menor custo possível. Assim, a tipificação das unidades produtivas foi feita de acordo com a área total (escala). Para cada uma das vinte e quatro microrregiōes homogêneas do Estado foram considerados dez tamanhos médios de propriedades, conforme especificado na Tabela 1.

${ }^{1}$ Este capfiulo baseia-se em Grawunder (1986). 


\section{TABELA 1 - Unidades Produtivas Típicas Adotadas no Modelo de Programação, por Tamanho de Área e Respectivo Código}

\begin{tabular}{cc}
\hline CÓDIGO & TAMANHO DE ÁREA (ha) \\
\hline T1 & $01-10$ \\
T2 & $101-20$ \\
T3 & $201-50$ \\
T4 & $501-100$ \\
T5 & $1001-200$ \\
T6 & $2001-500$ \\
T7 & $5001-1000$ \\
T8 & $10001-2000$ \\
T9 & $20001-5000$ \\
T10 & 5000 ou mais
\end{tabular}

FONTE: Elaborado pelos autores com base no Censo Agrícola da FIBGE, 1980.

Para cada uma das unidades típicas, foi elaborado um vetor insumo-produto, utilizando informações de tabelas especiais da FIBGE relativas ao Censo Agrifola de 1980. Neste vetor, foram inseridas informaçōes referentes à mixagem de produtos das unidades produtoras, custos de produção, valor da produção e requerimentos de terra $\mathrm{e}$ mão-de-obra.

O conjunto de restrições adotadas no modelo refere-se às disponibilidades de área total e mão-de-obra trimestral existentes na microrregiāo homogênea e, também, quanto ao mínimo de produção a ser alcançada para os produtos programados. Estes mínimos foram fixados em $95 \%$ do valor, observados no Censo de 1980 .

A partir da concepção básica, desenvolveram-se diversos modelos condicionados à hipótese eficiência-preço, visando quantificar impactos potenciais de políticas selecionadas sobre o setor primário gaúcho. Estes modelos e as políticas avalidas foram as seguintes:

a) Mínimo Custo (MINCUS) - Objetiva avaliar a eficiência econômica da agricultura do Estado, tendo por base o volume de produção levantada no Censo agrícola de 1980. 
b) Alimentos básicos (ALBAS) - Visa verificar a viabilidade de expandir a produçāo de produtos alimentares básicos, como: arroz, feijāo, milho, mandioca e leite. Foram testadas duas alternativas: aumento na produção de $10 \%$, modelo ALBAS 1; aumento de $20 \%$ na produção, modelo ALBAS 2.

c) Reestruturação Agråria (SEMLAT) - Tem por escopo avaliar possíveis efeitos de urna política agrária através da eliminaçăo das grandes propriedades. No modelo SEMLAT 1, foram excluldas, inicialmente, as propriedades com mais de 5000 ha (T10); no modelo SEMLAT 2, foram tirados os estabelecimentos com área maior do que 2000 ha (T9 e T10).

\section{1 - Resultados da Anạlise da Eficiência Produtiva}

O resumo dos resultados, obtidos nos diversos modelos desenvolvidos para analisar a eficiência produtiva da agricultura gaúcha, é cotejado, quando possivel, com a situação levantada no Censo Agropecuário de 1980 (Atual). Esta situação atual, para servir de base de comparação, foi reduzida para $95 \%$ do valor contabilizado no Censo, conformando-a, assim, com os limites mínimos de produçāo impostos aos modelos.

TABELA 2 - Efeitos na Agricultura Gaúcha de Políticas Agrícolas e Agrárias sobre Custo de Produção, Valor Bruto da Produção e Emprego (Situação Eficiente = 100)

\begin{tabular}{lccc}
\hline MODELO & $\begin{array}{c}\text { CUSTO } \\
\text { DE } \\
\text { PRODUÇÃO }\end{array}$ & $\begin{array}{c}\text { VALOR BRUTO } \\
\text { DA } \\
\text { PRODUÇÄO }\end{array}$ & $\begin{array}{c}\text { USO } \\
\text { DA }\end{array}$ \\
\hline ATUAO-DE-OBRA & 111 & 100 & 120 \\
MINCUS & 100 & 100 & 100 \\
ALBAS - 1 & 106 & 104 & 110 \\
ALBAS - 2 & 115 & 108 & 123 \\
SEMLAT - 1 & 106 & 104 & 115 \\
SEMLAT - 2 & 107 & 105 & 115 \\
\hline
\end{tabular}

FONTE: Resultados da pesquisa. 
Os resultados apresentados na tabela 2 mostram que o custo de produção atual é de apenas $11 \%$ superior àquele da situação de eficiência máxima. Este resultado sugere que, dada a rigidez estrutural da situação real e os riscos envolvidos na produção, o setor agrícola é bastante eficiente. Esta eficiência, entretanto, é condicionada à tecnologia empregada na época do Censo. Portanto, sempre existe a possibilidade de, com emprego de outra tecnologia, ampliar a produção, mesmo sem alterar sensivelmente a quantidade utilizada de recursos. Portanto, esta relativa eficiência não deve ser tomada como limite máximo.

Embora se possa observar que o setor agrícola é relativamente eficiente, em termos de minimização de custo, isto não significa que também o seja para a maximização de lucros. Considerando-se a situação atual, o valor bruto da produção em Cz\$ de 1980 foi de 189 milhōes, enquanto o custo de produção calculado alcançou 257 miIhões. Nota-se, pois, que o custo foi aproximadamente $36 \%$ maior do que o valor da produção, embora esta relação deva ser tomada com certa cautela, pois pode estar viesada pela forma como foi estruturado o custo.

O valor imputado para a mão-de-obra representa $50 \%$ do custo total de produção. É possível que este item do custo de produçảo tenha sido superestimado, tanto pela remuneração atribuilda pela mão-deobra, como pela quantidade da mesma empregada no setor. Mesmo assim, essa diferença é bastante significativa, e pode ser tomada como um indicativo de que os fatores de produção pertencentes às unidades produtivas estão tendo uma remuneração aquém do seu custo de oportunidade. Esta constatação é reforçada, ainda, pelo fato de que, no cálculo do custo de produção, não ter sido computado nenhuma remuneração para o fator terra, o que implicaria uma diferença ainda maior.

Outro ponto a destacar, é que a busca da eficiência tenderia a reduzir o emprego na agricultura, pois a situação atual, quando comparada com aquela de menor custo, emprega cerca de $20 \%$ mais de mão-de-obra. Nota-se que a reestruturação da produção agrícola tenderia a deslocar o homem do campo, o que se constitui num resultado esperado face a existéncia de subemprego no setor. Observa-se, também, que tanţ a eliminação das grandes propriedades como o incentivo à produção de alimentos tenderia a aumentar o emprego no meio rural, ao menos em relação à situação de custo mínimo. Com a redu- 
ção das grandes propriedades, a produção seria redistribuida para as menores e essas utilizam muito mais mão-de-obra do que aquelas. Da mesma forma, a expansão da produção de alimentos aumentaria o emprego pelo fato de serem as pequenas propriedades especializadas nesse tipo de produção.

Em contrapartida, a implementação dessas polfticas, agrilcola e agrária, aumentaria tanto os custos como o valor da produção. Porém, em ambos os casos, a relação custo/valor da produção ficaria abaixo da relação da situação atual. Isto significa que o desenvolvimento de tais pollticas nẩo colocaria o setor agrícola, ao menos em termos de eficiência-preço, numa situação pior do que a atual.

Outro resultado que se relaciona com a eficiência agrícola referese ao custo de oportunidade das atividades, pois o mesmo possibilita detectar se elas são ou não ineficientes. Os resultados encontrados na solução do modelo MINCUS são apresentados na tabela 3.

\section{TABELA 3 - Custos Marginais Relativos das Atividades Agro- pastoris da Agricultura Gaúcha - Solução Ótima do Modelo MINCUS}

\begin{tabular}{lc}
\hline ATIVIDADES & $\begin{array}{c}\text { CUSTOS MARGINAIS } \\
\text { RELATIVOS }^{2}\end{array}$ \\
\hline Bovinos & 0,99 \\
Sưnos & 0,40 \\
Aves & 0,76 \\
Leite & 3,10 \\
Ovos & 2,18 \\
Lã & 2,30 \\
Arroz & 0,67 \\
Feijáo & 9,40 \\
Mandioca & 2,30 \\
Milho & 1,10 \\
Soja & 0,97 \\
Trigo & 1,23 \\
Outros de Lavoura Temporária & 0,12 \\
Produtos de Lavoura Permanente & 0,52 \\
Hortitrutigranjeiros & 6,50 \\
Silvicultura e Extrativa Vegetal & 0,37 \\
\hline
\end{tabular}

FONTE: Resultados da pesquisa.

2 O Custo Marginal relativo do i-ésimo produto é definido como CMgi/Pi; onde CMgi e o custo adicional de produção da i-ésima atividade e Pi é o preço do produto $\mathrm{i}$. 
O custo marginal relativo, para uma atividade agricola qualquer, dentro das condições tecnológicas e limites de produção impostas no modelo MINCUS, representa sua eficiência relativa.

As atividades que têm um custo marginal relativo menor do que a unidade são consideradas eficientes. Esta eficiência decorre do fato de que uma unidade adicional da atividade gera uma receita (preço) maior do que o custo incremental. Em contra partida, aquelas que têm um custo marginal relativo maior do que a unidade são apontadas como ineficientes (não rentáveis). $O$ valor da produção, obtido pelo aumento de uma unidade da atividade, é menor do que o custo adicienal incorrido. Persistindo as condiçōes apresentadas na tabela 3, com o decorrer do tempo, se espera que haja um ajustamento no setor agrícola atravês de uma redução na quantidade ofertada e/ou aumento nos preços das atividades ineficientes e, vice-versa, para as eficientes. Este processo de ajustamento tenderia para um equilíbrio onde o custo marginal relativo de todas as atividades agrícolas se situaria próximo da unidade.

\section{3 - EFICIÊNCIA DO USO DO SOLO AGRÍCOLA ${ }^{3}$}

A análise econômica da consenvação de um recurso natural visa, basicamente, traçar uma estratégia ótima de seu uso no tempo. Tendo este objetivo em mente, desenvolveu-se uma pesquisa para avaliar 0 sistema atual do uso do solo agrícola do Estado e, simultaneamente, determinar planos śtimos de longo prazo para uma exploração adequada do mesmo. Selecionaram-se, para o estudo, as regióes denominadas de Planalto Médio e Missōes por possufrem características diversas de clima, tipo de solo, exploração comercial de grãos e técnicas de produção empregadas, permitindo que os resultados obtidos possam ser generalizados para outras áreas com características similares.

O modelo de análise utilizado considerou três aspectos para atingir aos objetivos propostos: a estrutura da degradação física do solo; a fertilidade química do solo; e as doenças no trigo.

a) $\mathrm{O}$ grau de degradação física do solo pode ser indicado pela sua resistência à erosão, sendo medida pela quantidade/intensidade de chuva requerida para arrastar uma tonelada de terra por hectare/ano.

\footnotetext{
3Este captulo baseia-se em Lanzer (1984)
} 
Como a queda de resistência do solo está associada à diminuição da porosidade, capacidade de retençāo de água e teor da matéria orgânica, tem-se que o efeito sobre a produtividade dos cultivos se processa de forma dinâmica. Assim, o uso do solo no ano anterior determinará o grau de degradaçăo do mesmo no ano atual que, por sua vez, influenciará a produtividade do que nele for cultivado e este influenciará o grau de degradação do próximo ano, fazendo que o processo seja dinâmico no tempo.

b) O grau de fertilidade química do solo também apresenta variações de ano para ano, podendo ser controlado pelo emprego de adubo. Desta forma, a fertilidade do solo depende do nivel do ano anterior e da adubação química realizada no ano corrente.

c) A intensidade de infestação de agentes patogênicos depende, basicamente, do uso do solo e do próprio grau de infestação do ano anterior. Sabe-se que o plantio sistemático de trigo no mesmo local, ano após ano, leva ao estoque crescente de esporos de doenças das ralzes, com queda sensível no seu rendimento.

Para o solo da região estudada, foram definidas quinze classes de degradação física, duas classes de fertilidade química e três de infestação de doenças do trigo, resultando num total de noventa estados posslveis para o solo. A passagem de uma classe de degradação flisica para outra, implica uma perda de $2,5 \%$ de produtividade. A caracterização do grau de degradação, em termos de resistência do solo à erosão pela chuva, foi definida por um indice de erosividade que associa o tempo e o volume de precipitação. A perda de resistência à erosão, estimada para o tipo de solo analisado, é de $5 \%$ ao ano.

Quanto à fertilidade química, adotou-se produtividade integral para a classe alta e de $80 \%$ para a média. A caracterização dessas classes, isto é, os requisitos de adubação e a produtividade relativa, associada a cada uma delas, foi baseada en estudos realizados anteriormente.

Os efeitos de doenças sobre a produtividade do trigo foram estimados a partir de experimentos realizados pela EMBRAPA. A partir deles, concluiu-se que o efeito depende da freqüência com que este cereal foi plantado no mesmo solo em safras passadas. Assim, a produtividade estimada em $75 \%$ se não houve nenhum intervalo de uma safra para outra, $80 \%$ se o cultivo é intercalado de uma safra sem plantio, e $90 \%$ se defasado com duas safras sem plantio.

A produtividade, absoluta dos cultivos, estimada para cada estado do solo, se obteve multiplicando a produtividade relativa dos mesmos 
pela expectância de produção máxima em condiçōes médias de clima. Adotando-se as seguintes expectâncias de produtividade máxima: $3200 \mathrm{Kg} / \mathrm{ha}$ para a soja; $2000 \mathrm{Kg} / \mathrm{ha}$ para o trigo; e $4800 \mathrm{Kg} / \mathrm{ha}$ para o milho. Calculou-se a receita e o custo de produção para cada um dos estados do solo. Deduzindo-se o custo da receita, obteve-se o retorno liquido de cada decisão, representando, em última análise, a remuneração do capital fundiário - terra mais benfeitorias - e a administração da propriedade, antes do pagamento dos impostos diretos.

A partir dos componentes bioeconômicos descritos acima, montaram-se as matrizes de probabilidade de transição e de retornos representativos do problema em estudo. Para a maximização da expectância do valor presente do retorno, adotou-se uma taxa de desconto de $6 \%$ ao ano e um horizonte de planejamento de até 50 anos.

O plano ótimo de longo prazo é definido como o plano para o qual converge o uso do solo quando é seguida uma estratégia que maximjza o valor presente dos retornos para um horizonte de planejamento. $A$ solução do modelo acima descrito resultou na busca desse plano para a região estudada.

\section{1 - Resultados da Análise Econômica da Conservação do Solo}

Os resultados obtidos no modelo indicam que o horizonte mínimo para o planejamento do uso ótimo do solo é de 11 anos. O plano de uso resultante sobre a estratégia ótima de decisão consiste na seguinte seqüência de cultivos: trigo/soja ou milho; adubação verde/soja ou milho; adubação verde/soja ou milho. Além disso, o plano ótimo conduz a uma concentração nos estados de maior conservação do solo, tanto física quanto química.

A meta a atingir, do ponto de vista do agricultor, consiste num plantio de trigo a cada três invernos, seguidos de dois invernos com adubação verde e cultivo comercial (soja/milho) no verão, sobre um solo com alta fertilidade química e degradaçāo física insignificante, características estas mantidas pela adubação qứmica e adubaçăo verde. Caso o solo se apresente, inicialmente, bastante degradado e com baixa fertilidade química, ele deve ser recuperado para ficar no mesmo estado previsto no plano ótimo. Neste caso, a estratégia ótima é a seguinte: adubação verde trienal para recuperação física do solo e correção de sua fertilidade com adubação química necessária. Ao final de 
três anos sem produção comercial, este solo atinge o estado visado, seguindo-se, dal em diante, a seqüência de cultivos referida no plano otimo.

Um plano alternativo àquele, na solução do modelo, seria cultivar o trigo em $1 / 3$ da área no inverno e os $2 / 3$ restantes com adubação verde e cultivos comerciais no verão. Nesse caso, a área com trigo deve seguir um sistema de rodízio. A adoção deste plano ótimo e suas repercussōes a nível da regiăo estudada foi analisada comparando-se os resultados com a situação atual. Para tanto, estimou-se, inicialmente, a situaçāo de degradação do solo na região, elaborando-se uma matriz de possibilidade de transição, baseada numa série histórica do índice de erodibilidade e de cultivos comerciais. Através da matriz de transição, concluiu-se que $70 \%$ da área considerada poderia ser enquadrada na classe 5 de degradação flsica e os restantes $30 \%$, na classe 14 . Como na área são cultivados, em média, 3,9 milhōes de hectares, aplicando-se este rateio, ter-se-ia que 2,73 milhões dos mesmos poderiam ser considerados como pertencentes a um nível moderado de degradação com potencial produtivo de $90 \%$, enquanto que 1,17 milhōes estariam numa faixa de degradação elevada, com potencial de $67,5 \%$ da capacidade produtiva original.

Em relaçąo à fertilidade química, estimou-se que a situação do solo da região seria a seguinte: $23 \%$ com fertilidade alta; $47 \%$ com fertilidade média e $30 \%$ com baixa fertilidade.

A partir desta situação-base, elaboraram-se dois cenários, cada qual representativo de um processo de produção para os cultivos da região. As características de cada cenário são as seguintes:

a) CENÁRIO PA - Com este cenário, procura-se projetar, para os próximos anos, a tendência do atual sistema de produção empregado na região. Pressupõe-se que os produtores utilizem as mesmas técnicas de cultivo, que mantenham a mesma mixagem de produtos e que a atual situação da fertilidade do solo seja mantida através do emprego de adubação quilmica. Admite-se, entretanto, que a degradação f́́sica do solo avança a cada ano de cultivo até permitir o máximo de produção equivalente a $65 \%$ do potencial produtivo original.

b) CENẢRIO ED - Este cenário consiste na implementação da estratégia ótima determinada anteriormente. Neste caso, parte-se da premissa de que os produtores não sǿ recuperem a fertilidade química do solo, mas também, que adotem o sistema de cultivo do plano ótimo que permita a recuperação f́sica do 'mesmo. A implementação da es- 
tratégia ótima parte das atuais condiçōes de degradação e fertilidade do solo.

A perda estimada de solo para a região, sob a situação atual, é de aproximadamente 21,59 t/ha/ano, podendo ser considerada como perda média. Este nível de erosão poderia ser reduzido em cerca de $61 \%$, se a estratégia ótima de cultivo, representada pelo cenário ED, fosse implementada na região. Essa perda de solo representava, na ocasião da pesquisa, em termos de perda de nutrientes, um custo equivalente à aquisição de $53,05 \mathrm{Kg}$ de nitrogênio. Além disso, esse valor de perda é apenas parcial, pois a ele deveriam ser acrescidos os custos das externalidades que são causadas fora da propriedade como: assoreamento de barragens, efeitos sobre a pesca e navegaçāo dos rios, poluiçăo da água por material em suspensāo, custos adicionais para reparar estragos causados na estradas, etc.

Para recuperar, química e fisicamente, o solo, seria necessário um aumento no emprego de fertilizantes corretivos, exceto nitrogênio, cuja quantidade poderia ser menor do que a atual. Esta queda na necessidade de nitrogênio é resultante da incorporação ao solo deste elemento, através da adubação verde, prevista no plano ótimo em $2 / 3$ da área no perlodo de inverno.

No que tange às informaçōes referentes à produção dos produtos agrícolas considerados, deve-se alertar que elas representam um potencial produtivo sob condições climáticas favoráveis, não podendo, portanto, ser tomadas como resultados definitivos. Entretanto, esta limitação não invalida as inferências que os resultados podem oferecer, visto que o importante são as diferenças relativas entre a produção de cada um dos cenários e nãao tanto os valores absolutos. Por outro lado, também é verdade que estas produtividades não são metas impossiveis de serem alcançadas, pois produtores da região já obtiveram resultados iguais e até mesmo superiores aos aqui estimados, empregando basicamente as mesmas técnicas de produção relacionadas no plano ótimo.

Tomando-se o cenário atual como referencial, pode-se observar que a produção de milho e soja poderia ser aumentada em torno de $50 \%$ se, além da correção química, o solo tivesse também sua degradação física recuperada. Resultado mais significativo é constatado para o trigo. $O$ potencial de produção da região com este cereal poderia 
ser aumentado em aproximadamente $68 \%$, se o plano śtimo fosse implementado. Esses resultados denotam a importância do cultivo adequado do solo, pois os ganhos adicionais em produtividade propiciariam uma receita mais do que suficiente para cobrir o incremento no custo de produção, conforme é mostrado pela relação benefício-custo do cenário que contempla o plano ótimo.

\section{4 - CONCLUSÕES}

Algumas informações relevantes para a agricultura gaúcha afloram dos resultados da análise desenvolvida acima, embora devam ser interpretadas dentro de certos parâmetros estabelecidos pela abrangência e qualificação dos modelos empregados. Em geral, as atividades deserıvolvidas no setor sāo conduzidas num limite de eficiência-preço muito próxirno do ótimo, principalmente se for levada em consideração a rigidez estrutural existente, os riscos envolvidos na produção, bem corro a tecnologia empregada. Todavia essa eficiência-preço não pode ser tomada corro sinônimo de eficiência econômica. Ao contrário, os resultados da análise mostraram que é possivel obterem-se melhores resultados com o emprego de alternativas de produção que visem, principalmente, a conservação do recurso solo agrícola. Caso esta situação persistir por mais tempo, pode-se esperar que a atividade agropastoril entre numa fase de estagnação ou até mesmo de declínio gradativo. Entretanto é preciso deixar claro que este quadro é relativo ao setor, quando tomado globalmente, não significando que seja válido para regiōes espeofficas ou que o mesmo seja irreverslvel. Os resultados da pesquisa, obtidos por técnicas de análise econômica normativa, mostram, via de regra, ser possível a reversão desta situação, bastando ampliar o horizonte de planejamento para buscar, individualmente, maximizar os resultados.

A supressão das grandes propriedades e, por conseguinte, a redistribuição da produção entre as unidades menores e a própria localização espacial da mesma, tende a piorar a relação eficiência-preço, quando esta é comparada com a situação ótima, embora ainda seja melhor do que a situação atual. Deve-se destacar que esta relativa eficiência-ineficiência observada, dados os preços, depende, em muito, da tecnologia que está sendo utilizada nas unidades produtivas. Neste particular, as ineficiências de certas atividades podem ser tomadas 
como um indicativo para priorizar pesquisas tecnológicas e/ou para orientar a atuação do serviço de extensão rural.

Por fim, a análise mostrou que a agricultura do Estado, mesmo dentro das limitaçōes atuais, comportaria um aumento na produção de produtos básicos de atendimento do mercado interno. A implementação de uma política neste sentido não afetaria, necessariamente, a produção dos demais produtos, bastando que houvesse uma reaglutinação de micro e pequenas unidades produtivas em estabelecimentos de porte médio, crédito rural com taxas de juros compatíveis e ampliação do atendimento ao produtor pelo serviço de extensão. Os ganhos em produção também seriam significantes, se as técnicas conservacionistas fossem empregadas. Os insumos exigidos para a recuperaçäo tísico-quilmica dos solos podem ser obtidos no Pals. Seria bastante, então, o delineamento de um plano que objetivasse ao fomento de tais práticas produtivas.

\section{BIBLIOGRAFIA}

GRAWUNDER, A.F.; LANZER, E.A.; MATTUELLA, J.L. (1986) - Um Modelo para Avaliação Quantitativa dos Efeitos de Políticas Agricolas sobre Questões de Eficiência e Eqüidade. Porto Alegre, IEPE/UFRGS. (Relatório de pesquisa não publicado).

LANZER, E.A.; MATTUELLA, J.L. (1984) - A Economia da Conservação de um Recurso Natural: O Solo Agricola no Sul do Brasil. Porto Alegre, IEPE/UFRGS. (Relatório de pesquisa não publicado).

LANZER, E.A. \& MATTUELLA, J. - Por que Conservar (ou não) os Recursos Naturais do Solo e da Água no Brasil: Implicações Econômicas a Nivel de Produtos. In: CONGRESSO BRASILEIRO DE ECONOMIA E SOCIOLOGIA RURAL, 22, Salvador, BA, 1984. Anais... Brasilia, SOBER, 1984A.

LANZER, E.A.; GRAWUNDER, A.F.; MATTUELLA, J.L. - Seleção de Áreas Prioritárias para Reforma Agrária por Programação Linear. In: SIMPÓSIO BRASILEIRO DE PESQUISA OPERACIONAL, 19, Rio de Janeiro, 1986. Anais... Rio de Janeiro, SOBRAPO, 1986. 
MATTUELLA, J.L.; LANZER, E.A.; GRAWUNDER, A.F. - Efeitos Potenciais de Pollticas Agnícolas sobre Eficiência e Eqüidade. In: CONGRESSO BRASILEIRO DE ECONOMIA E SOCIOLOGIA RURAL, 24, Lavras, MG, 1986. Anais... Brasília, SOBER, 1986, v.1, p.281-290. 